\title{
Preoperative anthropomorphic and nutritious status and fistula risk score for predicting clinically relevant postoperative pancreatic fistula after pancreaticoduodenectomy
}

Tomoyuki Abe ${ }^{1} \mathbb{D}$, Hironobu Amano ${ }^{1,2}$, Tsuyoshi Kobayashi $^{2}$, Keiji Hanada $^{3}$, Minoru Hattori ${ }^{4}$, Masahiro Nakahara ${ }^{1}$, Hideki Ohdan ${ }^{2}$ and Toshio Noriyuki ${ }^{1,2^{*}}$

\begin{abstract}
Background: Postoperative pancreatic fistula (POPF) is a life-threatening postoperative complication. The aim of this study was to evaluate the efficacy of the fistula risk score (FRS) and preoperative body composition factors for predicting the occurrence of clinically relevant POPF (CR-POPF) after pancreaticoduodenectomy (PD).

Methods: In this study, 136 consecutive patients who underwent PD between 2006 and 2018 were enrolled. The risk factors of CR-POPF (grades B and C) were analyzed. Preoperative visceral adipose tissue area (VATA), skeletal mass index (SMI), and subcutaneous adipose tissue area (SATA) were calculated from computed tomography data.

Results: The overall 30-day mortality and morbidity rates were 0.7 and $38 \%$, respectively. The incidence rates of grade $B$ and C CR-POPF were 27 and 4\%, respectively. A univariate analysis revealed that male sex, habitual smoking, prognostic nutritional index (PNI) $<45$, VATA $\geq 90$, VATA/SATA $\geq 0.9$, VATA/SMI $\geq 1.4$, and FRS $>4$ were significantly associated with the incidence of CR-POPF. A multivariate analysis revealed that $\mathrm{PNI}<45, \mathrm{VATA} / \mathrm{SMI} \geq 1.4$ and FRS $>4$ were the independent risk factors of CR-POPF.
\end{abstract}

Conclusions: Preoperative anthropomorphic imbalance, PNI, and FRS were independent risk factors for CR-POPF. Patients with high-risk factors should be closely monitored during the postoperative period.

Keywords: Fistula risk score, Pancreaticoduodenectomy, Postoperative pancreatic fistula, Skeletal muscle index, Visceral adipose tissue area

\footnotetext{
* Correspondence: t.abe.hiroshima@gmail.com

'Department of Surgery, Onomichi General Hospital, 1-10-23, Onomichi, Hiroshima 722-8508, Japan

${ }^{2}$ Department of Gastroenterological and Transplant Surgery, Graduate School of Biomedical and Health Sciences, Hiroshima University, Hiroshima, Japan Full list of author information is available at the end of the article
}

C C The Author(s). 2020 Open Access This article is licensed under a Creative Commons Attribution 4.0 International License, which permits use, sharing, adaptation, distribution and reproduction in any medium or format, as long as you give appropriate credit to the original author(s) and the source, provide a link to the Creative Commons licence, and indicate if changes were made. The images or other third party material in this article are included in the article's Creative Commons licence, unless indicated otherwise in a credit line to the material. If material is not included in the article's Creative Commons licence and your intended use is not permitted by statutory regulation or exceeds the permitted use, you will need to obtain permission directly from the copyright holder. To view a copy of this licence, visit http://creativecommons.org/licenses/by/4.0/. The Creative Commons Public Domain Dedication waiver (http://creativecommons.org/publicdomain/zero/1.0/) applies to the data made available in this article, unless otherwise stated in a credit line to the data. 


\section{Background}

Regardless of surgical technique and perioperative management after patients undergo pancreatic resection, the postoperative complication rate remains high at 20 to $50 \%$ [1-3]. Among the postoperative complications, severe POPF remains of utmost concern as it can result in massive bleeding. Various risk factors of postoperative pancreatic fistula (POPF) have been identified, including a narrow main pancreatic duct, soft pancreatic texture, perioperative blood transfusion, high body mass index (BMI), and sarcopenia [4-8]. Callery et al. reported that a simple 10-point Fistula Risk Score (FRS) evaluated during pancreaticoduodenectomy (PD) and calculated on the basis of gland texture, pathology, pancreatic duct diameter, and intraoperative blood loss, accurately predicts POPF [9].

In 2016, the International Study Group on Pancreatic Fistula (ISGPF) redefined POPF [10] and recognized its prevalence at $13-30 \%[1,4,5]$. Sarcopenia is defined as having a skeletal mass 2 standard deviations lower than the mean for healthy young adults $[11,12]$. Skeletal mass is calculated using computed tomography (CT) data. Sarcopenia affects muscle function and is strongly associated with both short-term outcomes and long-term prognosis $[7,11]$. Recent studies reported that an abundant visceral adipose tissue area (VATA) and a high ratio of VATA to skeletal muscle was associated with postoperative complications [13, 14]. Increased adipose tissue and sarcopenia deteriorate the host's immune system, increasing their susceptibility to postoperative complications such as POPF [7, 8]. The aim of this study was to determine the efficacy of using the approach to predicting potential risk factors of CR-POPF from preoperative CT using PNI and FRS scores.

\section{Methods}

\section{Patients}

A total of 136 patients who underwent PD between 2006 and 2018 at the Department of Surgery, Onomichi General Hospital, were enrolled in this study. Patients who received palliative surgery were excluded from the study. Clinical and pathological data and preoperative CT findings were collected. Patients with pancreatic ductal adenocarcinoma, adenocarcinoma of the papilla, extrahepatic cholangiocarcinoma, intraductal papillarymucinous carcinoma, and chronic pancreatitis were considered eligible. The study was approved by the local institutional review board (OJH-201642), and written informed consent was obtained from all the patients.

\section{Preoperative CT analysis of body composition}

Eight weeks prior to surgery, all the patients underwent a preoperative evaluation using non-enhanced and enhanced multi-detector CT (Discovery CT $750 \mathrm{HD}, \mathrm{GE}$
Healthcare, Milwaukee, WI, and Sensation 16, Siemens, Forchheim, Germany, respectively), with a section thickness of $2.5-5 \mathrm{~mm}$. The CT slices at the third lumbar vertebra (L3) level were analyzed using Advantage Workshop 4.5 (GE Healthcare) and Virtual Place Fujin (AZE Ltd., Tokyo, Japan). The body composition assessment included calculations of the visceral adipose tissue area (VATA), subcutaneous adipose tissue area (SATA), and skeletal muscle area. CT analysis was performed by trained investigators who were blinded to the patients' characteristics and clinical outcomes (HY, MY). The tissue Hounsfield unit (HU) thresholds were as follows: 29 to $150 \mathrm{HU}$ for the skeletal muscle area, -190 to -30 for the SATA, and - 150 to - 50 for the VATA. Skeletal muscle area was defined at the L3 level and included the psoas major and minor, paraspinal muscles (i.e., erector spinae and quadratus lumborum), and abdominal wall muscles (i.e., transversus abdominus, external and internal obliques, and rectus abdominis). The skeletal muscle area was normalized for height in meters squared $\left(\mathrm{m}^{2}\right)$ to obtain the skeletal muscle index (SMI). The VATA/SMI ratio was defined as high if $\geq 1.4$ and low if $<1.4$ (Fig. 1). The cutoff value was estimated using a receiver-operating characteristic (ROC) curve analysis.

\section{Definition of sarcopenia and pancreatic fistula}

Sarcopenia was defined as follows: in men, a SMI of < $43 \mathrm{~cm}^{2} / \mathrm{m}^{2}$ with a BMI of $<25 \mathrm{~kg} / \mathrm{m}^{2}$ or a SMI of $<53$ $\mathrm{cm}^{2} / \mathrm{m}^{2}$ with a BMI of $25 \mathrm{~kg} / \mathrm{m}^{2}$; and in women, a SMI of $<41 \mathrm{~cm}^{2} / \mathrm{m}^{2}$ [13]. Pancreatic fistula was defined in accordance with the current ISGPF criteria [10], and only fistulas of grades B and C were considered.

\section{Surgical procedure and postoperative care}

Surgery type was selected on the basis of tumor location. Subtotal stomach-preserving PD was routinely performed in the patients. Lymph nodes near the anterior and posterior surfaces of the pancreatic head were resected en bloc, and nodes of the superior mesenteric artery were resected en bloc when technically possible. The pancreatic stump was sutured using two-layer sutures end to end with the invagination of the jejunum. End-to-side hepaticojejunostomy was performed $5 \mathrm{~cm}$ distal to the pancreaticojejunostomy followed by side-toside gastrojejunostomy. A round drain was positioned near the pancreatic anastomosis; and a flat drain, near the biliary anastomosis. Epidurals and non-steroid antiinflammatory agents were routinely used during the procedure.

The patients with CR-POPF received total parenteral nutrition and octreotide (Sandostatin by Novartis, Rueil Malmaison, France), and a percutaneous drain was inserted under radiological guidance when the collection of infected fluid was suspected on CT. 

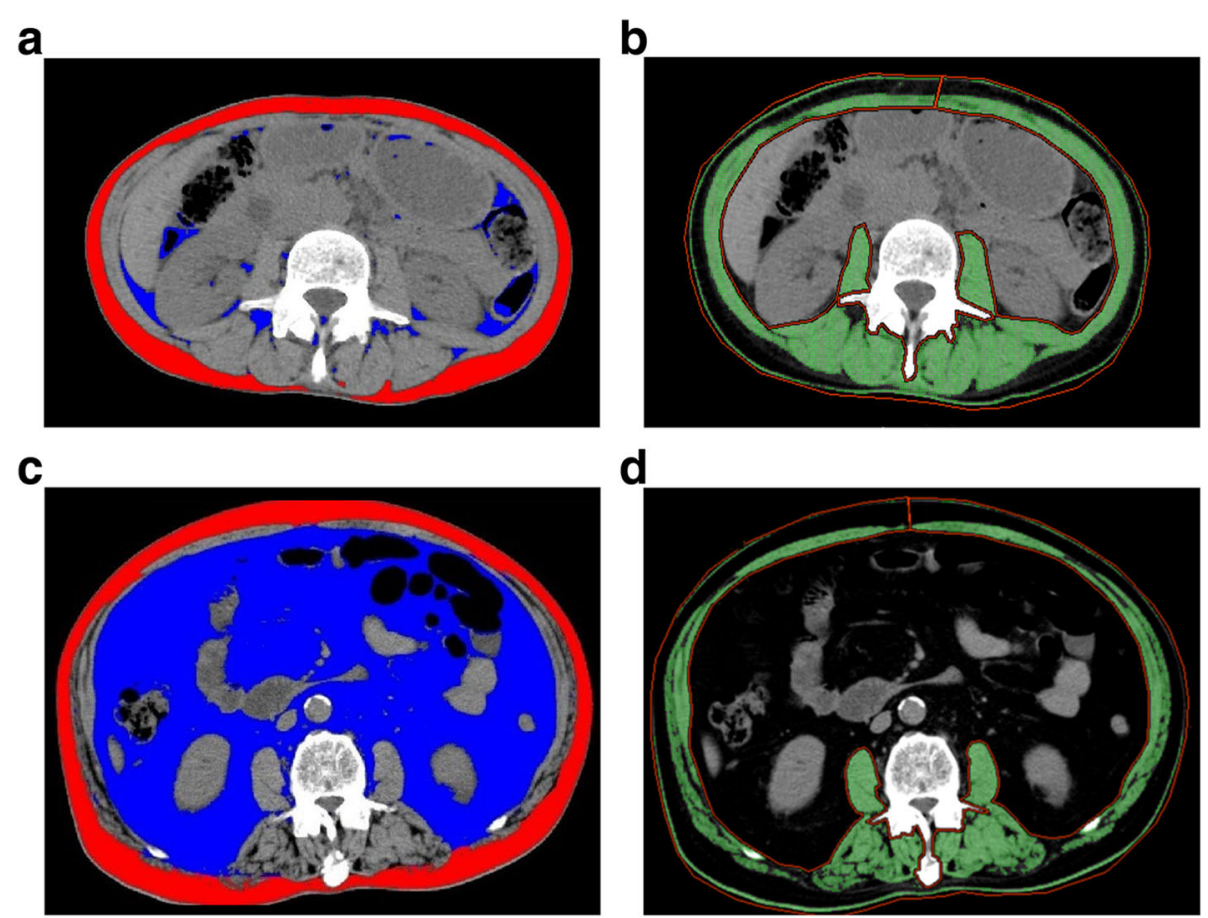

Fig. 1 Computed tomography (CT) images at the third lumbar vertebra level. The visceral adipose tissue area (VATA) is highlighted in blue, while the subcutaneous adipose tissue area (SATA) is highlighted in red. Areas of total skeletal muscle is highlighted in green. $\mathbf{a}, \mathbf{b} C T$ image of a patient with low VATA/skeletal muscle index (SMI; VATA, $8.0 \mathrm{~cm}^{2} / \mathrm{m}^{2}$; SATA, $43.8 \mathrm{~cm}^{2} / \mathrm{m}^{2}$; SMI, $40.5 \mathrm{~cm}^{2} / \mathrm{m}^{2}$; VATA/SMI, 0.20 ). c, d CT image of a patient with high VATA/SMI (VATA, $359.0 \mathrm{~cm}^{2} / \mathrm{m}^{2}$; SATA, $125.2 \mathrm{~cm}^{2} / \mathrm{m}^{2} ;$ SMl, $42.5 \mathrm{~cm}^{2} / \mathrm{m}^{2}$; VATA $/ S M I, 8.45$ )

\section{Statistical analysis}

Continuous variables were reported as medians and analyzed using the nonparametric Mann-Whitney $U$ test. Categorical variables were compared using the Fisher exact test. Logistic regression was used to model categorical outcomes. Variables that showed statistically significant associations in the univariate analysis were entered into a multivariate logistic regression model. Differences between the results of the comparative tests were considered significant if a two-sided $p$ value of $<$ 0.05 was obtained. An FRS of $>4$ was defined as high on the basis of the ROC curve analysis (Table 1). ROC curve analysis was applied to determine the cutoff values for the variables including PNI, VATA, SATA, SMI

Table 1 Fistula risk score for the prediction of clinically relevant pancreatic fistula after pancreatoduodenectomy

\begin{tabular}{|c|c|c|}
\hline Risk factor & Parameter & Points $^{a}$ \\
\hline \multirow[t]{2}{*}{ Gland texture } & Firm & 0 \\
\hline & Soft & 2 \\
\hline \multirow[t]{2}{*}{ Pathology } & Pancreatic adenocarcinoma of pancreatitis & 0 \\
\hline & Ampullary, duodenal, cystic, and islet cell & 1 \\
\hline \multirow[t]{5}{*}{ Pancreatic duct diameter, mm } & $\geq 5$ & 0 \\
\hline & 4 & 1 \\
\hline & 3 & 2 \\
\hline & 2 & 3 \\
\hline & $\leq 1$ & 4 \\
\hline \multirow[t]{4}{*}{ Intraoperative blood loss, mL } & $\leq 400$ & 0 \\
\hline & $401-700$ & 1 \\
\hline & $701-1000$ & 2 \\
\hline & $>1000$ & 3 \\
\hline
\end{tabular}


VATA/SMI, and VATA/SATA, which were determined to be independent risk factors. All the statistical analyses were performed using SPSS version 22 (IBM Corp., Armonk, NY).

\section{Results}

\section{Patient characteristics}

The median age of all the enrolled patients was 71 years (range, 35-86 years). Of the 136 patients enrolled, 94 were male and 42 were female. The overall 30 -day mortality and morbidity rates were $0.7 \%$ (1/136 patients) and $38 \%$ (51/136 patients), respectively. The incidence rates of grade B and C POPF were $27.2 \%$ (37/136 patients) and $3.7 \%$ (5/136 patients), respectively. The most common pathological diagnosis was pancreatic tumor, followed by tumors in the papilla of Vater and extrahepatic bile duct. Preoperative sarcopenia was diagnosed in 53 patients (39\%). The patients' characteristics are shown in supplemental Table 1 . The median VATA and SATA were 103.7 and $100.7 \mathrm{~cm}^{2} / \mathrm{m}^{2}$, respectively. The median score for FRS calculation was 4 (range, 0-9).

\section{Risk factors of POPF}

In the univariate analysis of the risk factors of POPF after pancreatectomy, male sex, habitual smoking, $\mathrm{PNI}<$ 45 , VATA $\geq 90$, VATA/SATA $\geq 0.9$, VATA/SMI $\geq 1.4$, and FRS $>4$ were identified to be significantly associated with POPF (Table 2). The multivariate analysis results indicated that $\mathrm{PNI}<45$, VATA/SMI $\geq 1.4$ and FRS $>4$ score were independent risk factors of POPF.

\section{Discussion}

The results of our study demonstrate that high VATA/ SMI, PNI $<45$ and high FRS score were independent risk factors of POPF after PD. Patients with three risk factors were significantly more likely to have CR-POPF after PD. Previous reports that examined the relationship between sarcopenia and POPF focused only on skeletal muscle mass and visceral adipose tissue $[8,13,15]$. Sandini et al. reported that a high visceral adipose tissue-toskeletal muscle ratio was a determinant of major postoperative complications after PD for malignancies [14]. Sui et al. reported that sarcopenia was not related to POPF,

Table 2 Univariate and multivariate analyses of risk factors of postoperative pancreatic fistula after pancreatectomy

\begin{tabular}{|c|c|c|c|c|c|c|}
\hline \multirow[t]{2}{*}{ Variable } & \multicolumn{2}{|l|}{ Univariate analysis } & \multicolumn{4}{|l|}{ Multivariate analysis } \\
\hline & Non-POPF $(n=94)$ & POPF $(n=42)$ & $p$ Value & Hazard ratio & $95 \% \mathrm{Cl}$ & $p$ Value \\
\hline Age $\geq 75$ years & $35(37 \%)$ & $12(29 \%)$ & 0.339 & & & \\
\hline Male & $60(64 \%)$ & $34(81 \%)$ & 0.048 & 1.195 & $0.286-4.990$ & 0.807 \\
\hline $\mathrm{BMI} \geq 25 \mathrm{~kg} / \mathrm{m}^{2}$ & $14(15 \%)$ & $11(26 \%)$ & 0.150 & & & \\
\hline Diabetes mellitus & $22(23 \%)$ & $5(12 \%)$ & 0.163 & & & \\
\hline Habitual smoking & $43(45 \%)$ & $28(67 \%)$ & 0.027 & 2.571 & $0.938-7.051$ & 0.067 \\
\hline Habitual alcohol consumption & 37 (39\%) & $22(52 \%)$ & 0.193 & & & \\
\hline Preoperative biliary drainage & $34(36 \%)$ & $12(29 \%)$ & 0.437 & & & \\
\hline $\mathrm{T}-\mathrm{Bil} \geq 1 \mathrm{mg} / \mathrm{dL}$ & $67(71 \%)$ & $28(67 \%)$ & 0.686 & & & \\
\hline Alb $\geq 3.5 \mathrm{mg} / \mathrm{dL}$ & $66(70 \%)$ & $34(81 \%)$ & 0.290 & & & \\
\hline $\mathrm{CRP} \geq 1 \mathrm{mg} / \mathrm{dL}$ & $19(20 \%)$ & $9(21 \%)$ & 1.000 & & & \\
\hline $\mathrm{PNI}<45$ & $51(54 \%)$ & $31(74 \%)$ & 0.037 & 2.659 & $1.045-6.767$ & 0.040 \\
\hline Sarcopenia & $40(43 \%)$ & $13(31 \%)$ & 0.254 & & & \\
\hline VATA $\geq 90 \mathrm{~cm} 2 / \mathrm{m} 2$ & 39 (41\%) & $32(76 \%)$ & 0.0002 & & & \\
\hline $\mathrm{SATA} \geq 88 \mathrm{~cm} 2 / \mathrm{m} 2$ & $55(59 \%)$ & $28(67 \%)$ & 0.448 & & & \\
\hline $\mathrm{SMI}<42 \mathrm{~cm} 2 / \mathrm{m} 2$ & $36(38 \%)$ & $10(24 \%)$ & 0.099 & & & \\
\hline VATA/SATA $\geq 0.9$ & $45(48 \%)$ & $32(76 \%)$ & 0.003 & 0.712 & $0.180-2.809$ & 0.627 \\
\hline VATA/SMI $\geq 1.4$ & $52(55 \%)$ & $39(93 \%)$ & 0.0004 & 14.712 & $3.064-70.650$ & 0.001 \\
\hline FRS high score (> 4 score) & $36(38 \%)$ & $30(71 \%)$ & 0.006 & 4.820 & $1.960-11.855$ & 0.001 \\
\hline Pancreatic adenocarcinoma or pancreatitis & $45(48 \%)$ & $24(57 \%)$ & 0.357 & & & \\
\hline Soft pancreatic texture & $42(45 \%)$ & $30(71 \%)$ & 0.005 & & & \\
\hline Pancreatic duct size $<3 \mathrm{~mm}$ & $33(35 \%)$ & $28(67 \%)$ & 0.0011 & & & \\
\hline Estimated blood loss > $701 \mathrm{~mL}$ & $47(50 \%)$ & $22(52 \%)$ & 0.849 & & & \\
\hline
\end{tabular}

Abbreviations: Alb albumin; Amy amylase; $B M I$ body mass index; $C l$ confidence interval; $C r$ creatinine; $C R P$ C-reactive protein; $P O D$ postoperative day; $P O P F$ postoperative pancreatic fistula; PNI prognostic nutritional index; SATA subcutaneous adipose tissue area; SMI skeletal muscle index; $T$-Bil total bilirubin; VATA visceral adipose tissue area; WBC white blood cells

Variables in bold show statistically significant association $(p<0.05)$. All the variables are expressed as number (percentage) 
and patients with non-sarcopenia were strongly associated with POPF [16]. Another report showed that sarcopenia was an independent risk factor of POPF [7]. BMI, which is mainly a reflection of obesity, has been consistently reported as a risk factor of POPF [4]. Considering these reports, a close evaluation of body composition along with evaluations of BMI and sarcopenia could be effective for predicting POPF. Therefore, our VATA/ SMI metric may be useful for a more precise evaluation of visceral fatty tissue and skeletal muscle imbalance. Some observations in this present study require clarification with respect to our higher CR-POPF rate than previously reported. First, there was a relatively high rate of soft pancreas and narrow main pancreatic size $<3 \mathrm{~mm}$. Twenty-seven patients (60\%) among those with PDAC were diagnosed with the disease at less than the pTNM stage I. The early detection of pancreatic cancer is correlated with long-term survival; however, obstructive pancreatitis caused by tumor progression did not occur in these patients. This could have increased the CR-POPF, even in patients with PDAC. Second, in the reconstruction, the pancreatic stump was sutured using two-layer sutures end to end with the invagination. Due to the relatively high rate of POPF, our reconstruction approach was recently changed to modified Blumgart anastomosis.

The underlying mechanism that links body composition and POPF still needs to be elucidated. Lutz et al. showed that the development of visceral adipose tissue is associated with an elevated production of proinflammatory molecules such as leptin, chemerin, resistin, tumor necrosis factor- $\alpha$, interleukin (IL) 1 , and IL-6 [17]. These proinflammatory cytokines suppress the host immune system and impede wound healing, thereby increasing susceptibility to infectious complications. Another line of thought suggests that in cancer patients, visceral adipose tissue may further disrupt certain catabolic pathways that promote the multimodal development of sarcopenia [18]. Sarcopenia itself may develop as a result of aging, catabolic disorders, cancer, and deficient nutrition, as well as impeded host immune activity through suppressed production of IL-15 [19]. Skeletal muscle tissue produces high levels of IL-15, which normally prevents muscle protein degradation and contributes to the regulation of adipose tissue formation and differentiation. The negative feedback induced by procytokines likely plays a key role in the development of POPF after pancreatectomy.

From a surgical point of view, the presence of abundant visceral adipose tissue may interfere with anastomosis creation, which could result in increased intraoperative bleeding and operation time. Perioperative blood loss should be minimized to protect the patient's immune system. In addition to high VATA, we determined other risk factors of POPF from pathological findings and postoperative clinical data.

The present multivariate analysis identified that the most effective predictor of CR-POPF was VATA/SMI. High BMI has a well-known association with obesity and surgical complications [20, 21]. Patients with a high proportion of body fat frequently have comorbidities such as diabetes mellitus, hypertension, and chronic heart failure. Obesity rates vary worldwide with low rates in Asia and high rates in America and Europe. Obesity status and BMI are both calculated using a weight-to-height ratio without a detailed consideration of body composition. In fact, the same BMI can be obtained with a large proportion of either total body adipose tissue or total muscle mass. Therefore, preoperative VATA and SMI assessments can provide reliable parameters for the prediction of POPF development and are advantageous because such evaluations could be applied worldwide.

Preoperative nutritional support and rehabilitation programs to decrease the risk of POPF are often implemented for patients with sarcopenia and poor nutritional status. Kaido et al. reported a positive impact of nutritional therapy on prognosis after living-donor liver transplantation especially in patients with sarcopenia [22]. However, multidisciplinary approaches will be required to prevent POPF in patients at high risk.

Several limitations of our study should be mentioned. First, this was a single-institution study, and the data were analyzed retrospectively. In addition, only Asian patients were included. Further studies are required to assess the feasibility of VATA/SMI, PNI, and FRS in predicting CR-POPF development.

\section{Conclusions}

In conclusion, our study demonstrates that preoperative body composition, defined by both visceral adipose tissue and skeletal muscle, are strong predictors of POPF incidence after pancreatectomy. Assessment of preoperative body composition is easy to perform, and reliable measurements can be obtained. Clinicians should closely monitor patients with a $\mathrm{PNI}<45$ and VATA/SMI $\geq 1.4$.

\section{Supplementary information}

Supplementary information accompanies this paper at https://doi.org/10. 1186/s12876-020-01397-7.

Additional file 1: Table 1. Clinicopathological data.

Abbreviations

Alb: Albumin; Amy: Amylase; BMI: Body mass index; Cl: Confidence interval; CR-POPF: Clinically relevant postoperative pancreatic fistula; $\mathrm{Cr}$ : Creatinine; CRP: C-reactive protein; FRS: Fistula risk score; HU: Hounsfield unit; ISGPF: the International Study Group on Pancreatic Fistula;

PD: Pancreaticoduodenectomy; POD: Postoperative day; POPF: Postoperative pancreatic fistula; PNI: Prognostic nutritional index; ROC: Receiver-operating characteristic; SATA: Subcutaneous adipose tissue area; SMI: Skeletal muscle 
index; T-Bil: Total bilirubin; VATA: Visceral adipose tissue area; WBC: White blood cells

\section{Acknowledgements}

We thank the Center of Life Sciences at Hiroshima University for allowing the use of their facilities.

\section{Availability data and materials}

The datasets used and/or during current study are available from the corresponding author on reasonable request.

\section{Authors' contributions}

$\mathrm{TA}$ and $\mathrm{HA}$, conception and design of the research, and writing the paper; $\mathrm{TA}, \mathrm{KH}, \mathrm{TK}, \mathrm{MN}$ and $\mathrm{MH}$ analysis and interpretation of data; $\mathrm{HO}, \mathrm{TN}, \mathrm{MN}$, and $\mathrm{KH}$, critical revision of the article for important intellectual content; and $\mathrm{HA}$, final approval of the article. All authors read and approved the final manuscript.

\section{Funding}

None.

\section{Ethics approval and consent to participate}

The study was approved by the local Institutional Review Board of Onomichi general hospital (OJH-201642), and written informed consent was obtained from all patients.

\section{Consent for publication}

Not applicable.

\section{Competing interests}

The authors declare that they have no competing interests.

\section{Author details}

${ }^{1}$ Department of Surgery, Onomichi General Hospital, 1-10-23, Onomichi, Hiroshima 722-8508, Japan. ²Department of Gastroenterological and Transplant Surgery, Graduate School of Biomedical and Health Sciences, Hiroshima University, Hiroshima, Japan. ${ }^{3}$ Department of Gastroenterology, Onomichi General Hospital, Hiroshima, Japan. ${ }^{4}$ Advanced Medical Skills Training Center, Institute of Biomedical and Health Sciences, Hiroshima University, Hiroshima, Japan.

Received: 7 December 2019 Accepted: 22 July 2020

Published online: 08 August 2020

\section{References}

1. Kimura W, Miyata $\mathrm{H}$, Gotoh $\mathrm{M}$, et al. A pancreaticoduodenectomy risk model derived from 8575 cases from a national single-race population (Japanese) using a web-based data entry system: the 30-day and in-hospital mortality rates for pancreaticoduodenectomy. Ann Surg. 2014;259:773-80.

2. Simons JP, Shah SA, Ng SC, et al. National complication rates after pancreatectomy: beyond mere mortality. J Gastrointest Surg. 2009;13:1798805.

3. Sledzianowski JF, Duffas JP, Muscari F, et al. Risk factors for mortality and intra-abdominal morbidity after distal pancreatectomy. Surgery. 2005;137: 180-5.

4. Aoki S, Miyata $\mathrm{H}$, Konno $\mathrm{H}$, et al. Risk factors of serious postoperative complications after pancreaticoduodenectomy and risk calculators for predicting postoperative complications: a nationwide study of 17,564 patients in Japan. J Hepatobiliary Pancreat Sci. 2017;24:243-51.

5. Fuks D, Piessen $G$, Huet $E$, et al. Life-threatening postoperative pancreatic fistula (grade C) after pancreaticoduodenectomy: incidence, prognosis, and risk factors. Am J Surg. 2009;197:702-9.

6. Gaujoux S, Cortes A, Couvelard A, et al. Fatty pancreas and increased body mass index are risk factors of pancreatic fistula after pancreaticoduodenectomy. Surgery. 2010;148:15-23.

7. Nishida $Y$, Kato $Y$, Kudo M, et al. Preoperative sarcopenia strongly influences the risk of postoperative pancreatic fistula formation after pancreaticoduodenectomy. J Gastrointest Surg. 2016;20:1586-94.

8. Pecorelli N, Carrara G, De Cobelli F, et al. Effect of sarcopenia and visceral obesity on mortality and pancreatic fistula following pancreatic cancer surgery. Br J Surg. 2016;103:434-42.
9. Callery M, Pratt W, Kent T, et al. A prospectively validated clinical risk score accurately predicts pancreatic fistula after pancreatoduodenectomy. J Am Coll Surg. 2013;216:1-14.

10. Bassi C, Marchegiani G, Dervenis C, et al. The 2016 update of the international study group (ISGPS) definition and grading of postoperative pancreatic fistula: 11 years after. Surgery. 2016;138:8-13.

11. Martin L, Birdsell L, Macdonald N, et al. Cancer cachexia in the age of obesity: skeletal muscle depletion is a powerful prognostic factor, independent of body mass index. J Clin Oncol. 2013;12:1539-47.

12. Baumgartner RN, Koehler KM, Gallagher D, et al. Epidemiology of sarcopenia among the elderly in New Mexico. Am J Epidemiol. 1998;147:755-63.

13. Sandini M, Bernasconi DP, Ippolito D, et al. Preoperative computed tomography to predict and stratify the risk of severe pancreatic fistula after pancreatoduodenectomy. Medicine (Baltimore). 2015;94:e1152.

14. Sandini M, Bernasconi DP, Fior D, et al. A high visceral adipose tissue-toskeletal muscle ratio as a determinant of major complications after pancreatoduodenectomy for cancer. Nutrition. 2016;32:1231-7.

15. House MG, Fong Y, Arnaoutakis DJ, et al. Preoperative predictors for complications after pancreaticoduodenectomy: impact of BMI and body fat distribution. J Gastrointest Surg. 2008;12:270-8.

16. Sui K, Okabayshi T, Iwata J, et al. Correlation between the skeletal muscle index and surgical outcomes of pancreaticoduodenectomy. Surg Today. 2018;48(5):545-51.

17. Lutz CT, Quinn LS. Sarcopenia, obesity, and natural killer cell immune senescence in aging: altered cytokine levels as a common mechanism. Aging (Albany NY). 2012;4:535-46.

18. Argiles JM, Busquets S, Stemmler B, Lopez-Soriano FJ. Cachexia and sarcopenia: mechanisms and potential targets for intervention. Curr Opin Pharmacol. 2015;22:100-6.

19. Quinn LS. Interleukin-15: a muscle-derived cytokine regulating fat-to-lean body composition. J Anim Sci. 2008;86:E75-83.

20. Dindo D, Muller MK, Weber M, Clavien PA. Obesity in general elective surgery. Lancet. 2003;361:2032-5.

21. McAuliffe JC, Parks K, Kumar P, et al. Computed tomography attenuation and patient characteristics as predictors of complications after pancreaticoduodenectomy. HPB (Oxford). 2013;15:709-15.

22. Kaido T, Ogawa K, Fujimoto $Y$, et al. Impact of sarcopenia on survival in patients undergoing living donor liver transplantation. Am J Transplant. 2013;13:1549-56.

\section{Publisher's Note}

Springer Nature remains neutral with regard to jurisdictional claims in published maps and institutional affiliations.

Ready to submit your research? Choose BMC and benefit from:

- fast, convenient online submission

- thorough peer review by experienced researchers in your field

- rapid publication on acceptance

- support for research data, including large and complex data types

- gold Open Access which fosters wider collaboration and increased citations

- maximum visibility for your research: over $100 \mathrm{M}$ website views per year

At $\mathrm{BMC}$, research is always in progress.

Learn more biomedcentral.com/submissions 